\title{
Interface Microstructure Investigation of Babbitt- Carbon Steel Composite Using Flux with Glycerol and Petroleum Jelly Additives
}

\author{
Naglaa Fathy \\ Department of Physics \\ College of Science \\ University of Hail \\ Hail, Saudi Arabia \\ naglaaf2002@yahoo.com
}

\begin{abstract}
The influence of adding glycerol and petroleum jelly during the tinning process of steel shell base of Babbitt-steel bimetal is studied in this paper. The morphology of interface layer is changed from a discontinuous layer in case of using flux+tin to a continuous one by adding glycerol or petroleum jelly to the flux+tin mixture. Also, the nterface layer thickness and the unbonded interface layer area increase by adding glycerol or petroleum jelly to flux+tin mixture due to their physical properties.
\end{abstract}

Keywords-Babbitt; steel; flux; glycerol; petroleum jelly

\section{INTRODUCTION}

Depending on the specific application requirements (corrosion resistance, wear resistance, electrical conduction, etc.), the working face layer of a bimetal should be characterized by high performance properties [1-3]. Tin-based Babbitt alloys are usually used as working surface layers, especially in sliding bearings. Tin-based Babbitt alloys are mainly composed of $\mathrm{Sn}-\mathrm{Sb}-\mathrm{Cu}$ containing about $0.5-8 \% \mathrm{Cu}$ and less than $8 \% \mathrm{Sb}$. The microstructures of tin-based Babbitt alloys are characterized by a solid solution matrix in which needles of $\mathrm{Cu}_{6} \mathrm{Sn}_{5}$ copper-rich constituent and fine, rounded particles of precipitated $\mathrm{SbSn}$ are distributed. The proportion of the copper rich constituent increases with copper content containing about $0.5-8 \% \mathrm{Cu}$ and higher percentage of $\mathrm{Sb}$ and $\mathrm{Sb}$ which exhibit primary cuboids of $\mathrm{SbSn}$, beside copper-rich constituent in the matrix [4-6]. Although, Babbitt-steel bimetal alloys are widely used materials for sliding bearings, the production of high performance Babbitt-steel bimetals still needs more effort due to the poor wettability of the steel with Babbitt alloy. Fluxing and tinning processes are usually used to improve the adhesion of the Babbitt layer on steel substrate [7, 8]. Usually, after grinding the surface of the steel substrate shell, it is briefly immersed in multi-chlorides aqueous flux solution $(24 \mathrm{~kg}$ zinc chloride, $6 \mathrm{~kg}$ sodium chloride, $3 \mathrm{~kg}$ ammonium chloride, 1L HCI, and enough water to make 100L) for 60 seconds followed by coating of the steel surface with either pure tin (Sn) or a Sn-lead alloy (called tinning process) to promote adhesion between the bearing and the Babbitt metal $[7,8]$.

The current study is investigating the interface microstructure of Babbitt-steel by using a mixture of powder tin, flux and glycerol and a mixture of powder tin, flux and petroleum jelly additives. The mixing of the powder tin with flux as one direct tinning process is successfully used for fabricating Babbitt-steel bimetal composite that is promising for flat and horizontal bearing applications [9]. Glycerol and petroleum jelly are added to the tin-flux mixture to facilitate tin-flux application for curvature surface steel shells.

\section{EXPERIMENTAL WORK}

Carbon steel base specimens with a chemical composition that is shown in Table I of dimension $400 \times 400 \times 9 \mathrm{~mm}^{3}$ are grinded with sand papers of 240 and 320-grit for two minutes each. The homemade flux is prepared using the chemicals listed in Table II mixed with the tin powder. The tin to flux ratio is $1: 5$ ( $1 \mathrm{~g}$ of tin, and $5 \mathrm{~g}$ of flux). The necessity of using flux in bimetal production is the fact that the oxides which always form up on all the brightened metal surfaces prevent the proper joining of the pieces. The flux by removing the oxides allows the tin to stick directly to the metal.

TABLE I. STEEL CHEMICAL COMPOSITION (WT \%)

\begin{tabular}{|c|c|c|c|c|c|}
\hline $\mathbf{C}$ & $\mathbf{M n}$ & $\mathbf{C r}$ & $\mathbf{N i}$ & $\mathbf{C u}$ & $\mathbf{F e}$ \\
\hline 0.15 & 0.33 & 0.03 & 0.05 & 0.02 & Bal. \\
\hline
\end{tabular}

TABLE II. FLUX CHEMICAL COMPOSITION WT \%, ML.

\begin{tabular}{|c|c|c|c|c|}
\hline $\mathbf{Z n C l}_{\mathbf{2}}$ & $\mathbf{N a C l}_{\mathbf{2}}$ & $\mathbf{N H}_{\mathbf{4}} \mathbf{C l}$ & $\mathbf{H C l}$ & $\mathbf{H}_{\mathbf{2}} \mathbf{O}$ \\
\hline $24 \mathrm{~g}$ & $6 \mathrm{~g}$ & $3 \mathrm{~g}$ & $1 \mathrm{ml}$ & $1 \mathrm{ml}$ \\
\hline
\end{tabular}

In the current research work, fluxing and tinning processes are merged in one step by mixing the flux with the tin powder. This research work aims to study the effect of the homemade tinning mixture of flux with glycerol and petroleum jelly additives on tinning quality and bonding characteristics of the 
steel Babbitt bimetal. Influence of the different tinning mixtures on the microstructure mechanical properties and bonding characteristics of the carbon steel Babbitt bimetal is studied for three groups of samples

- The first group of steel Babbitt bimetal was produced using flux $+\operatorname{tin}(5: 1$ ratio).

- The second group was produced using homemade flux+tin+glycerol (ratio 4:1:1)

- The third group was produced using homemade flux+tin+petroleum jelly (vaseline) in a ratio of 4:1:1.

Glycerol and petroleum jelly are used to study their effects on the evaporation process, the homogeneity of the tinning mixture, and how it holds the flux in its place. If the flux is easy to distribute and able to hold in its place, this will make it good for curved surfaces. In the tinning process $1 \mathrm{~g}$ of the tinning mixture is distributed on the steel base shell. Then the base is placed on a preheated hot plate of $360^{\circ} \mathrm{C}$ for $5 \mathrm{~min}$. After heating time the steel shell is removed from the hot plate and the tinned surface is cleaned using towel and tap water. Then the samples are cooled to room temperature. Babbitt metal with the chemical composition shown in Figure 3 is melted in an electrical furnace at $400^{\circ} \mathrm{C}$. After holding for about $30 \mathrm{~min}$ the crucible of molten metal is removed from the furnace and is poured onto metallic mold containing a preheated (at $360^{\circ} \mathrm{C}$ for $7 \mathrm{~min}$.) tinned steel shell. The volume of liquid Babbitt to solid steel ratio is kept to be 1:1.

TABLE III.

CHEMICAL COMPOSITION OF THE BABBIT TIN BASE ALLOY

\begin{tabular}{|c|c|c|c|}
\hline Element & Sb & Cu & Sn \\
\hline Wt.\% & $6.5-7.5$ & 2.5 & Bal. \\
\hline
\end{tabular}

In order to reveal the microstructure of the bimetal interface region between the Babbitt and the carbon steel base, metallographic examination is conducted by optical microscopy. Optical examination is conducted after grinding, polishing, and etching with $4 \%$ nital to define any discontinuities, crack, lack of bonding, voids, holes etc. The measurements were taken for as cast samples of the three groups of the carbon steel Babbitt bimetal.

\section{RESULTS AND DISCUSSION}

It is reported in [7] that the microstructure of Babbitt has a significant influence on the operating life of lined bearings. For $\mathrm{Sn}$ based Babbitt, the percentage of $\mathrm{Sb}$ and $\mathrm{Cu}$ alloyed with $\mathrm{Sn}$ controls the microstructure constituents. In the current study (see Figure 1(a)) and previous ones [4-6] it is reported that tinbased Babbitt alloys that contain about $2.5 \% \mathrm{Cu}$ and about 6.5 $7.5 \% \mathrm{Sb}$ usually have a microstructure of a solid solution matrix, distributed needles of $\mathrm{Cu}_{6} \mathrm{Sn}_{5}$ copper-rich constituent and rounded particles SbSn precipitate. The strength and hardness of Babbitt with a fine-grained microstructure is $20 \%$ higher than that of a Babbitt with a coarser-grained microstructure. It is reported in [10] also that the shear stress and ultimate strength of the bond between the Babbitt alloy and the metal shell are higher for the fine-grained Babbitt compared with the coarse one.

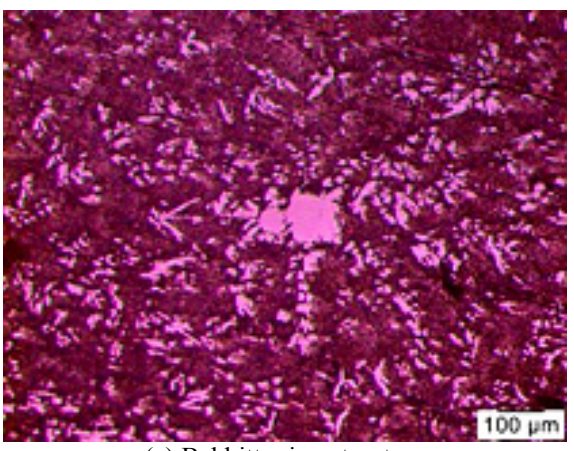

(a) Babbitt microstructure

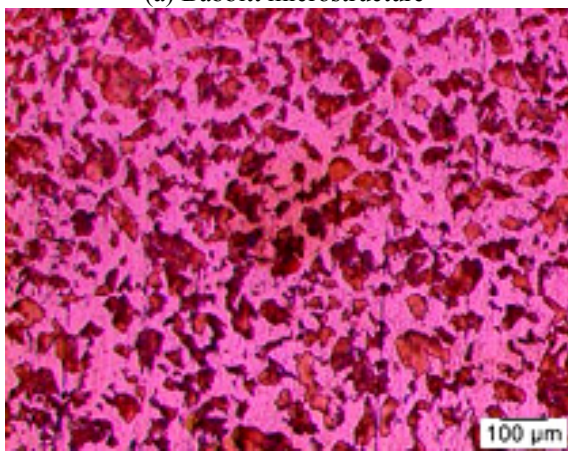

(b) Steel base microstructure

Fig. 1. Microstructures of Babbitt steel base region.

Figure 1 shows the microstructures of the Babbitt alloy and the steel base regions. The microstructure of steel region shows mainly ferrite matrix and some pearlite due to lower carbon percentage. For all the conditions of bimetal casting in the current research, microstructures of Babbitt working surface and steel solid base show the same constituents. Figure 2 shows the interface microstructure of as-cast Babbitt-steel bimetal for three different groups after applying fluxing and tinning processing conditions. Group 1 shows the interface microstructure of the sample prepared using flux and tin. Group 2 shows the interface microstructure of the sample prepared using flux, tin and glycerol. Group 3 shows the interface microstructure of the sample prepared using flux, tin and petroleum jelly. It is clear that addition of glycerol and petroleum jelly to the mixture of flux and tin has a significant effect on the morphology of the interface zone of Babbitt- steel bimetal castings. Using flux+tin produces a discontinuous interface layer, while by using additions of glycerol or petroleum jelly produces a continuous interface layer. Figure 3 shows the effect of flux type on interface layer thickness for samples prepared using flux+tin, flux + tin + glycerol and flux+tin+petroleum jelly. It is clear that by using flux+tin (Group 1) a minimum interface layer thickness of $150 \mu \mathrm{m}$ is achieved. The addition of glycerol or petroleum jelly to flux+tin increases the interface layer thickness that reaches about $240 \mu \mathrm{m}$ for the glycerol addition case.

It is reported in [11-12] that the bonding energy of the bimetal interface when using $\mathrm{Sn}$ as an intermediate layer is relatively $10 \%$ larger compared to that of the bimetal interface without a Sn layer. So, Babbitt and steel bimetal interfacial bonding performances with an intermediate layer of Sn are better than those of an interface without Sn layer. In the current 
research, by the addition of glycerol or petroleum jelly, a continuous interface Sn layer is achieved instead of the discontinuous $\mathrm{Sn}$ layer in the case of flux+tin only. This means that the addition of glycerol or petroleum jelly is stronger and more stable during pouring the molten Babbitt on the tinned steel base. Our current gravity casting technique is still the standard method of applying Babbitt to bearing steel shells. This process involves the use of a preheated tinned steel shell. Many process parameters should be considered in order to fabricate a high performance and long life Babbitt-steel bimetal bearing. One parameter of most importance is the tinning process. The optimization of the tinning process is essential for achieving a good strength bond between Babbitt and steel shell. Although, the addition of glycerol and petroleum jelly to the flux and tin mixture stabilized the Sn layer, the unbonded area increases (see Figure 4), although further research on the optimum percentage should follow.

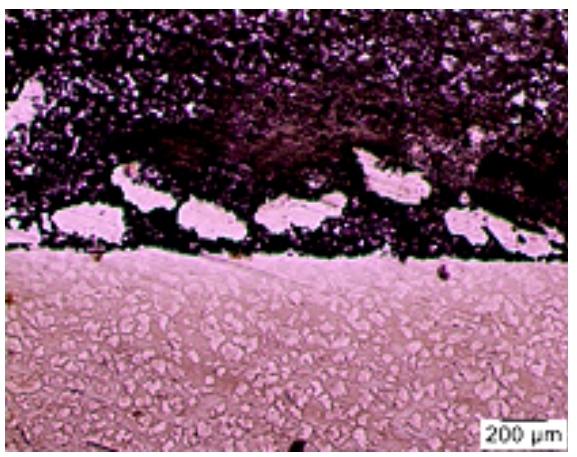

(a) Flux + tin

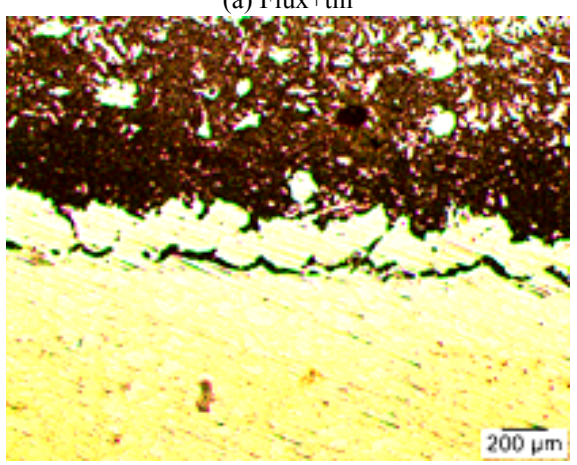

(b) Flux + tin + glycerol

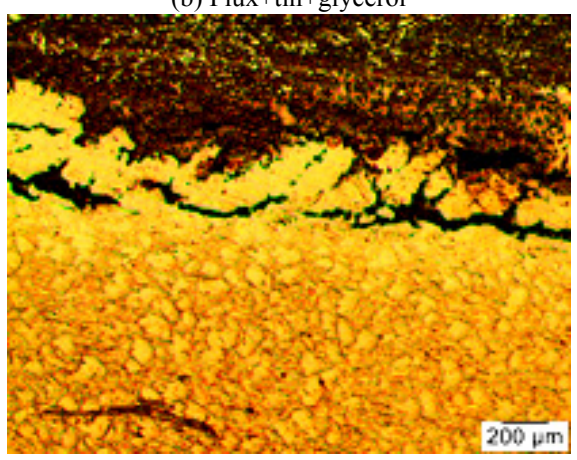

(c) Flux+tin+petroleum jelly

Fig. 2. Interface microstructure of three samples made by using different combinations of flux, tin, glycerol and petroleum jelly.

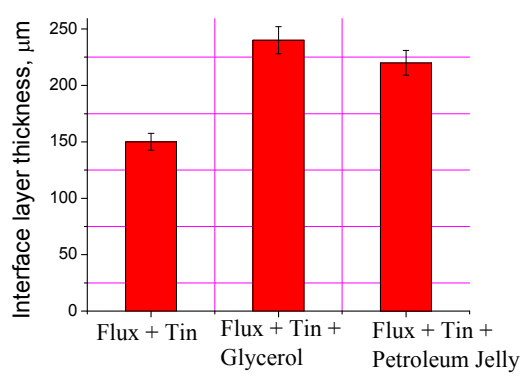

Fig. 3. The effect of flux type on the tin layer thickness for samples prepared using flux + tin, flux + tin + glycerol and flux + tin + petroleum elly.

(a)

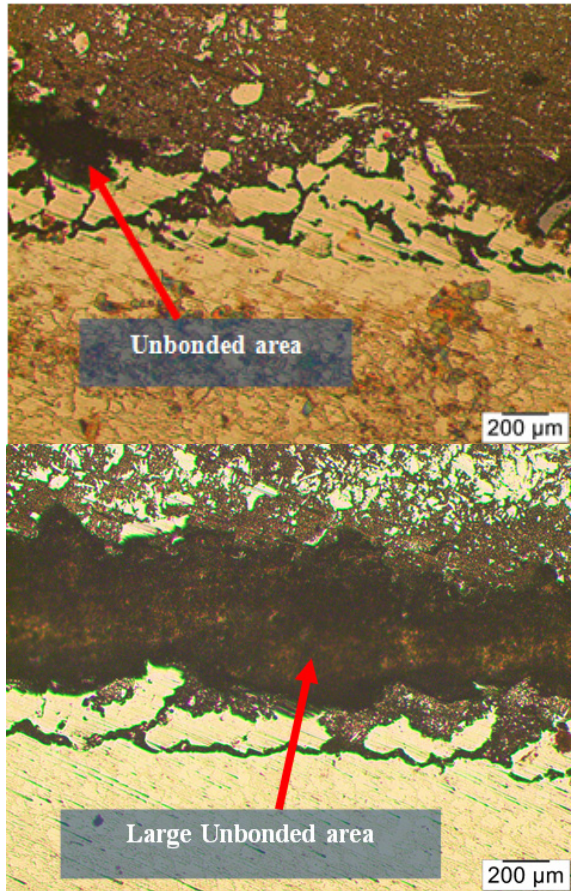

Fig. 4. Microstructure of Babbitt bimetal for samples prepared using a) Flux+tin+petroleum jelly b) Flux+tin+glycerol

The typical interface microstructures of as-cast samples with addition of glycerol and petroleum jelly are shown in Figure 4. The addition of glycerol or petroleum jelly to flux +tin mixture increases the unbonded interface area (Figure 5). The largest unbonded area is observed by addition of glycerol to the flux+tin mixture. The interface has partial joint, which is characterized by the presence of the so-called "bimetallic connecting bridges" or unbounded areas. It is believed that the unbounded areas are a result of the gases produced by the combustion of glycerol or petroleum jelly residuals in the tinning layer during the preheating process and pouring of the Babbitt. It is well known that petroleum jelly and glycerol are not physically similar. Petroleum jelly is mainly a non-polar hydrophobic hydrocarbon and insoluble in water otherwise glycerol is mainly an alcohol that is strongly hydrophilic. This means that petroleum jelly is water-repelling material and on the other side glycerol is water-attracting material. The physical properties of glycerol explain that why large unbonded 
areas are observed by adding it to the flux+tin mixture. Petroleum jelly is flammable only when heated to liquid. Its product fumes are light. Generally, glycerol is considered to be a crucial part of the production of antifreeze and waxes. Also it is used to generate resins, paints and waxes, for creating cleaning and purifying agents for soldering. Residual glycerol and/or petroleum jelly in the preformed tinned surface layer have great influence on the morphology and the formation of unbonded areas in the interface between Babbitt and steel. This effect is significant in adding glycerol due to its attractive nature for water besides producing fumes after pouring molten Babbitt metal.

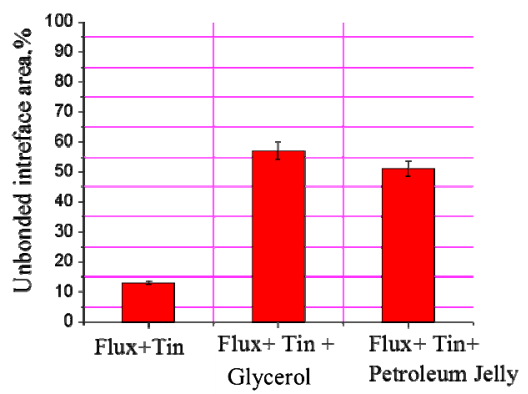

Fig. 5. The effect of flux type on unbonded interface area

\section{CONCLUSIONS}

The effect of adding glycerol and petroleum jelly to flux+tin mixture on interface morphologies of Babbitt-steel bimetal composites was investigated. Based on the obtained results, the main conclusions can be summarized as:

- The morphology of the interface layer is changed from discontinuous in case of using flux+tin to continuous by adding glycerol or petroleum jelly to the mixture.

- The thickness of the interface layer increases by addition of glycerol or petroleum jelly to the mixture.

- Unbonded interface layer area increases by the addition of glycerol or petroleum jelly to flux+tin mixture due to their physical properties.

- More future investigations using a small percentage addition of glycerol or petroleum jelly to flux+tin mixture, long tinning heating time and higher Babbitt pouring temperature are needed to improve the quality of interface bond between Babbitt and steel alloys.

\section{ACKNOWLEDGMENT}

The author would like to thank Dr. Mohamed Ramadan of Casting Technology Lab., Manufacturing Technology Dept., CMRDI, - Egypt for the useful discussion and technical support.

\section{REFERENCES}

[1] T. Wróbel, "Characterization of Bimetallic Castings with an Austenitic Working Surface Layer and an Unalloyed Cast Steel Base", Journal of Materials Engineering and Performance, Vol. 23, No. 5, pp. 1711-1717, 2014

[2] M. Ramadan, K. M. Hafez, K. S. Abdel Halim, N. Fathy, T. Chiba, H. Sato, Y. Watanabe, "Influence of Heat Treatment on Interface Structure of StainlessSteel/Gray Iron Bimetallic Layered Castings", Applied Mechanics and Materials, Vol. 873, pp. 3-8, 2017

[3] M. Ramadan, "Interface Characterization of Bimetallic Casting with a 304 Stainless Steel Surface Layer and a Gray Cast Iron Base", Advanced Materials Research, Vol. 1120-1121,pp. 993-998, 2015

[4] R. R. Dean, C. J. Eavans, "Plain bearing materials: the role of tin", Tribology International,Vol. 9, No. 3, pp. 101-108, 1976

[5] G. C. Pratt, "Materials for plain bearings", International Metallurgical Reviews,Vol. 18, No. 2, pp. 62-88, 1973

[6] M. Moazami Goudarzi, S. A. Jenabali Jahromi, A. Nazarboland, "Investigation of characteristics of tin-based white metals as a bearing material", Materials and Design, Vol. 30, No. 6, pp. 2283-2288, 2009

[7] P. Diouf, A. Jones, "Investigation of Bond Strength in Centrifugal Lining of Babbitt on Cast Iron" Metallurgical And Materials Transactions A, Vol. 41, No. 3, pp. 603-609, 2010

[8] P. K. Liaw, M. N. Gungor, W.A. Logsdon, Y. Ijiri, B. J. Taszarek, S. Frohlich, "Effect of Phase Morphologies on the Mechanical Properties of Babbitt-Bronze Composite Interfaces", Metallurgical Transactions A Vol. 21, No. 2, pp. 529-538, 1990

[9] N. Fathy, M. Ramadan, "Influence of Vol. Ratio of Liquid to Solid and Low Pouring Temperature on Interface Structure of Cast Babbitt-Steel Bimetal Composite", AIP Conference Proceedings 1966, pp. 020028-1020028-6, AIP Publishing, 2018

[10] A. G. Gromyko, "Influence of Casting Method of Plain Bearings on the Structure of Babbitt", Metal Science and Heat Treatment, Vol. 32, No. 9 , pp. 708-711, 1990

[11] J. Wang, Q. Xia, Y. Ma, F. Meng, Y. Liang, Z. Li, "Interfacial Bonding Energy on the Interface between $\mathrm{ZChSnSb} / \mathrm{Sn}$ Alloy Layer and Steel Bodyat Microscale", Materials, Vol. 10, No. 10, p. 1128, 2017

[12] J. Koutsky, J. Vesela, "Evaluation of white metal adhesion (conventional casting and thermal wire arc spraying) by ultrasonic non-destructive method", Journal of Materials Processing Technology, Vol. 157-158, pp. $724-728,2004$ 